\title{
Necrotizing fasciitis complicating female genital mutilation: case report
}

\author{
Abdalla A. Mohammed ${ }^{7}$ and Abdelazeim A. Mohammed ${ }^{7}$
}

\section{Introduction}

Necrotizing fasciitis is a deep-seated infection of the subcutaneous tissue that results in the progressive destruction of fascia and fat; it easily spreads across the fascial plane within the subcutaneous tissue [1]. It begins locally at the site of the trauma, which may be severe, minor or even non-apparent. The affected skin becomes very painful without any grossly visible change. With progression of the disease, tissues become swollen, often within hours. Skin colour may progress to violet and blisters may form, with subsequent necrosis of subcutaneous tissues.

Necrotizing fasciitis is caused by many types of bacteria such as group A streptococcus, Vibrio vulnificus, Clostridium perfringens, Bacteroides fragilis, commonly known as "flesh-eating bacteria"; Group A streptococcus is the most common cause [2]. The disease has also been referred to as haemolytic streptococcal gangrene, Meleney ulcer, acute dermal gangrene, hospital gangrene, suppurative fasciitis, and synergistic necrotizing cellulitis. Fournier gangrene is a form of necrotizing fasciitis that is localized to the scrotum and perineal area.

Patients with necrotizing fasciitis typically have a high fever and appear veryill. Very severe cases progress within hours and the mortality rate is as high as $40 \%[3,4]$.

Here we report a rare case of necrotizing fasciitis complicating female genital mutilation (FGM).

\section{Case report}

A 7-year-old girl presented to Kassala New Hospital on 2 March 2005 with high fever following FGM. The procedure had been done 7 days prior to admission in a mass female genital cutting in the village during the first week of the school summer vacation. After the cutting, a herbal powder was applied to the wound. No antibiotic was given. During that period she experienced high fever and difficulty in passing urine. When her condition deteriorated, her family decided to bring her to the hospital.
On examination the she was very ill; she had a temperature of $40.2^{\circ} \mathrm{C}$, pulse of 104 beats per minute and blood pressure of $90 / 60 \mathrm{mmHg}$. There was extensive perineal and anterior abdominal wall necrosis (Figure 1). The left labium majus, the lower three-quarters of the left labium minus and most of the mons pubis were eaten away. The clitoris was preserved. There was extensive loss of skin and subcutaneous fat of the right inguinal region. Superficial skin ulceration reached the umbilicus.

After initial resuscitation, she was catheterized with a Foley catheter and intravenous ceftriaxone was given.

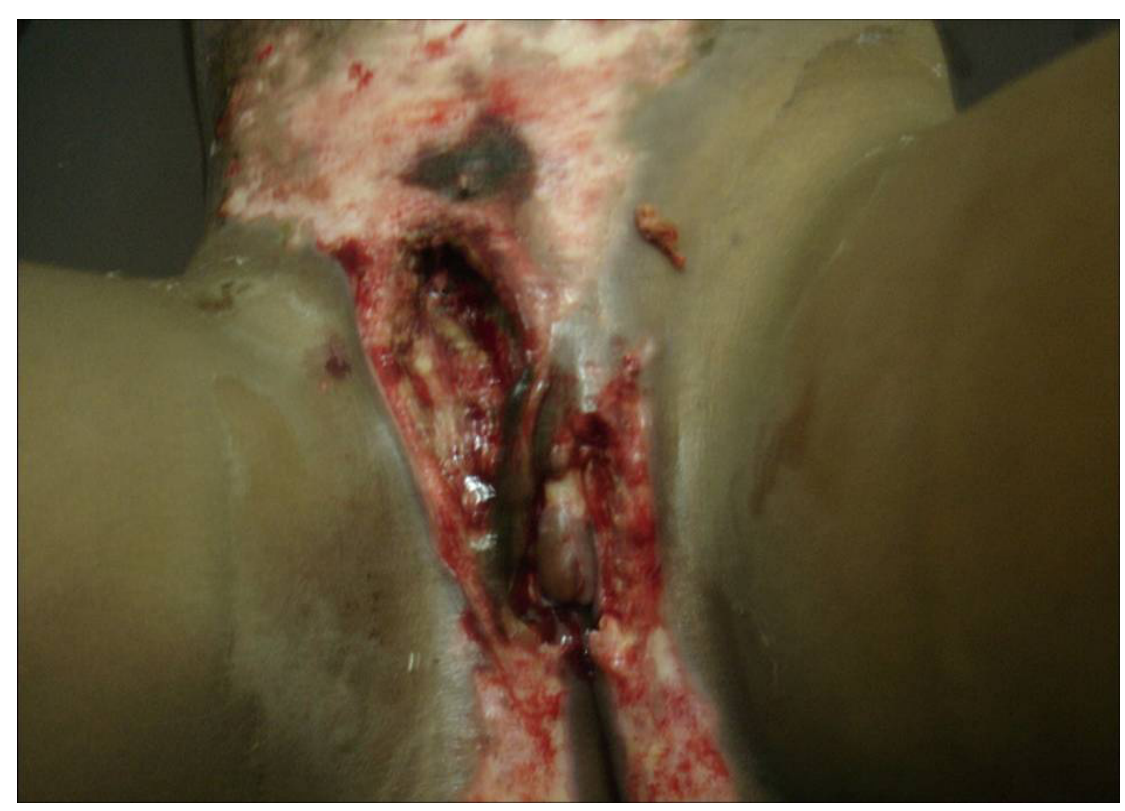

Figure 1 Case of necrotizing fasciitis: extensive perineal and anterior abdominal wall necrosis is evident 
Debridement of the wound was performed under general anaesthesia. With repeated debridement and dressing, she showed progressive improvement. Wound swab culture showed group A streptococcal growth that was sensitive to the drug prescribed.

After 7 days her family took her away from hospital and she was not seen again.

\section{Discussion}

We report a rare case of necrotizing fasciitis complicating FGM to highlight the danger of this practice. FGM is defined by the World Health Organization, United Nations Children's Fund and United Nations Family Planning Association as "the partial or total removal of the female external genitalia or other injury to the female genital organs for cultural or other non-therapeutic reasons" [5]. Four types of FGM are recognized: type 1 involves excision of the prepuce, with or without excision of part or the entire clitoris; type II involves excision of the clitoris with partial or total excision of the labia minora; type III involves excision of part or all of the external genitalia and stitching/narrowing of the vaginal opening (infibulation); and type IV pricking, piercing or incising of the clitoris and/or labia - this last type is not commonly practised in Sudan.

Most girls undergo FGM when they are between 7 and 10 years old [6]. Almost all those who have undergone it experience pain and bleeding. The intervention itself is traumatic as girls are usually physically held down during the procedure. Those who are cut often have their legs bound together for several days or weeks. The immediate consequences that have been documented include severe pain, shock, excessive bleeding, difficulty in passing urine, infections, death and psychological consequences. Since such complications are usually documented only when the girl or woman seeks hospital treatment, the true extent of immediate complications is unknown. Mortality rates due to FGM are not known due to underreporting, but Hoskin thought it to be high in regions where FGM is practiced [7]. Women with FGM are significantly more likely to have obstetric complications compared with those without FGM [8].

An estimated $89 \%$ of Sudanese girls undergo the procedure [9].

In our case, the girl was brought to hospital late, after her condition had deteriorated. As seen in the figure, she had undergone type I FGM, which is called by some "sunna" to give it a religious reference.
Treatment consisted of broad spectrum antibiotics and exploration of the affected area under general anaesthesia. Incision of fascia to relieve tension with multiple sequential debridement was done. She showed progressive improvement and the catheter was removed after 6 days. Skin grafting would have been done if she had stayed to complete treatment. However, her family removed her from hospital after 7 days and before this could be done.

Given her condition, it is likely that fibrosis and contractures of anterior abdominal wall muscles will result from the FGM. The external genitalia will also be defective causing dyspareunia and difficult labour. This girl is at high risk of being taken for repair of her defective circumcision outside health facilities.

Usually parents will not reveal the identity of the practitioner, who is usually an experienced traditional practitioner, a health worker (midwife or nurse), a doctor and sometimes female gynaecologist. In 2008, 2 female doctors (a gynaecologist and a community physician) wrote in a famous daily newspaper advocating in favour of FGM and admitting that they practised type 1 [10].

We would like to highlight the danger of this procedure even if it is done in its simplest form and even if performed by medical practitioners.

\section{References}

1. Catena $\mathrm{F}$ et al. Necrotizing fasciitis: a dramatic surgical emergency. European journal of emergency medicine, 2004, 11:44-8.

2. Giuliano A et al. Bacteriology of necrotizing fasciitis. American journal of surgery, 1977, 134:52-7.

3. Taviloglu $\mathrm{K}$ et al. Idiopathic necrotizing fasciitis: risk factors and strategies for management. American surgeon, 2005, 71(4):315-20.

4. Yanar $\mathrm{H}$ et al Fournier's gangrene: risk factors and strategies for management. World journal of surgery, 2006, 30(9):1750-4.

5. Female genital mutilation: a joint WHO/ UNICEF/UNFPA statement. Geneva, World Health Organization, 1997.

6. Egypt Demographic and Health Survey, 1995. Cairo, Egypt, National Population Council and Calverton, MD, Macro International, 2006:175.
7. Hosken F. The Hosken Report: genital and sexual mutilation of females, 4th ed. Lexington, MA, Women's International Network, 1993:37.

8. Banks E et al. WHO study group on female genital mutilation and obstetric outcome. Lancet, 2006, 367(9525):1835-41.

9. Safe Motherhood Survey 2001. Sudan, Federal Ministry of Health (FMoH), Central Bureau of Statistics (CBS), and United Nation Population Fund (UNFPA), 2001.

10. Elbashier AA. تاصيل ختان الاناث [Encouraging female circumcision]. Al-Sudani Newspaper, 4 February 2008:8 (Issue No. 801). 